\title{
A influência da idade e do tempo de experiência na ocorrência de acidentes de trabalho no segmento sucroalcooleiro
}

\section{The influence of age and time of experience on the work accidents in the sugar- alcohol segment}

Antonio Francisco Lopes da Silva ${ }^{1 *}$, José Luís Garcia Hermosilla ${ }^{1}$, Jorge Alberto Achcar ${ }^{1}$, Guilherme Afonso Rodrigues ${ }^{1}$, Ethel Cristina Chiari da Silva ${ }^{1}$

\begin{abstract}
RESUMO
Os acidentes do trabalho têm sido considerados um problema de saúde pública em virtude de seus impactos socioeconômicos e das limitações que impõem ao trabalhador e à economia do país. O perfil do trabalhador tem se mostrado diretamente ligado à ocorrência destes eventos, e sua compreensão tem contribuído para o desenvolvimento de políticas de natureza prevencionista. O objetivo desta pesquisa é identificar se há relação entre os fatores idade, tempo de experiência, e o setor de trabalho com o envolvimento em acidentes de trabalho e sua gravidade. A pesquisa quantitativa de natureza exploratória-descritiva, tomou como base os registros de acidentes de trabalho documentados pelo Departamento de Segurança do Trabalho de uma empresa de grande porte do setor sucroalcooleiro, de um contingente de 770 trabalhadores de uma usina durante 2 anos safra (2015/16 e 2017/17). Os resultados apontam que os fatores idade e o setor ao qual o trabalhador pertence são os fatores mais associados a frequência dos acidentes e a sua gravidade. As análises reforçam a importância dos programas de treinamento em segurança do trabalho e do direcionamento de programas de treinamento de segurança mais específicos aos trabalhadores do setor industrial.
\end{abstract}

Palavras-chave: Acidente do trabalho; Setor sucroalcooleiro; Perfil do acidentado; Idade; Tempo de experiência.

\section{ABSTRACT}

Occupational accidents have been considered a public health problem due to their socioeconomic impacts and the limitations they impose on workers and on the country's economy. The worker's profile has been directly linked to the occurrence of these events, and their understanding has contributed to the development of prevention policies. The aim of this research is to identify the relationship of the factors age, time of experience, and the work sector with the work accidents and their severity. The quantitative descriptive research based on the records of work accidents documented by the Department of Occupational Safety of a large company in the sugar-alcohol sector. The data collection involved 770 workers of a plant who worked during 2 crop years (2015/16 and 2017/17). The results indicate that the age and the work sector are the factors most associated with the frequency of accidents and their severity. The analyses reinforce the importance of job safety training programs and the targeting of more specific safety training programs for industrial workers.

Keywords: Work accident; Sugar and alcohol sector; Accident profile; Age; Time of experience.

\footnotetext{
${ }^{1}$ Universidade de Araraquara (UNIARA).*E-mail: toninhotreinamento@yahoo.com.br
} 


\section{INTRODUÇÃO}

No Brasil, a Lei 8.213 de 1991 que dispõe sobre os benefícios da Previdência Social, em seu artigo 19, define acidentes do trabalho como todo evento que decorra do exercício do trabalho, a serviço da empresa e que provoque lesão corporal ou perturbação funcional que leve à morte ou à redução, permanente ou temporária, da capacidade para o trabalho.

Freitas (2011) afirma que, dizer que o acidente de trabalho é um acontecimento inesperado e que não pode ser previsto é uma ideia antiga e ultrapassada, e não pode mais ser levada em consideração nos dias de hoje, pois grande parte dos acidentes de trabalho ocorre devido à falta de prevenção dos riscos que o colaborador pode se envolver.

Para Teixeira e Freitas (2003) o tipo de atividade desenvolvida e o ambiente de trabalho estão diretamente ligados à ocorrência de acidentes que podem acontecer com qualquer tipo de trabalhador, e segundo estes autores, os principais riscos ocupacionais presentes no ambiente de trabalho, são: físicos, mecânicos, biológicos, ergonômicos e psicossociais. Atheneu (2003) complementa dizendo que o trabalho é nocivo quando as tarefas exigidas pela organização podem, de certa maneira, reduzir a segurança do trabalhador.

Batiz, Santos e Licea (2009) afirmam que a qualidade de vida dos trabalhadores está diretamente ligada com o que é disponibilizado para estes para que possam exercer suas atividades laborais. No caso do setor sucroalcooleiro, Scopinho (2000) investigando trabalhadores que exercem atividades rurais neste segmento, afirma que o adoecimento destes profissionais é explicado em grande parte por conta da maneira como o trabalho é organizado e realizado. Neste mesmo segmento, Alessi e Scopinho (1994) afirmam que as atividades realizadas são geralmente realizadas em ambientes que expõem os trabalhadores a situações de periculosidade e penosidade.

Além das características da atividade, outros fatores também exercem influência sobre o bem estar do trabalhador e seu desempenho no trabalho, como a idade, que segundo Crawford et al. (2010) pode provocar tanto mudanças físicas quanto psicológicas em trabalhadores a partir dos 50 anos, mostrando em pesquisas que os trabalhadores mais velhos com idade superior a 55 anos, são os que possuem um menor risco de acidente em comparação aos trabalhadores mais jovens de 25 a 40 anos de idade. 
Apesar do risco de acidentes diminuir com a idade do trabalhador, trabalhos mostram que a gravidade destes eventos quando ocorrem não acompanha essa mesma tendência, como aponta Laflamme e Menckel (1995) quando afirmam que é muito importante relacionar as questões de segurança e saúde no trabalho com o fator idade, o que leva a defender a teoria do envelhecimento decremental, que mostra que o enfraquecimento progressivo que surge devido à idade, leva à redução das capacidades laborais dos indivíduos e a um aumento de acidentes mais graves.

O fator idade também esteve presente nas constatações de Ribeiro (2015) que investigou 650 acidentes de trabalho em pesquisa nos registros do SINAM (Sistema de Informação de Agravos e Notificação de Acidentes Graves) da 17ª região, no Estado do Paraná, entre os anos de 2011 a 2013, revelando que a maioria (36\%) ocorrem com trabalhadores na faixa etária de 41 a 80 anos, seguidos pelos empregados da faixa etária de 21 a 30 anos (30,5\%). Segundo o autor o fato de ocorrer acidentes com maior frequência envolvendo os trabalhadores mais velhos se explica pela diminuição da resistência muscular, reflexos mais lentos e enfraquecimento da visão e audição.

Outro aspecto importante neste contexto é o tempo de experiência do trabalhador, que segundo Oh e Shin (2003) está diretamente ligado à ocorrência de acidentes de trabalho, sendo que, quanto mais anos de experiência, menor será a probabilidade da ocorrência de lesões no trabalho. Pegatin e Xavier (2008) mostram que os trabalhadores com tempo de experiência maior apresentam um índice de fadiga menor em relação aos trabalhadores com menos tempo de experiência, e demonstram que os trabalhadores com mais tempo de empresa, possuem melhores habilidades motoras, pois desenvolvem estratégias biomecânicas que reduzem a sobrecarga nos ossos e nos músculos, diminuindo assim, o risco de acidentes.

Em função da importância de se conhecer o perfil dos acidentes de trabalho e se seus aspectos associados, do destaque econômico do segmento sucroalcooleiro para o País e das limitações de pesquisas na área, a pergunta que se coloca diante do segmento a ser investigado é: qual o papel do fator idade e do tempo de experiência nos acidentes de trabalho do segmento sucroalcooleiro?

O objetivo deste trabalho foi descobrir possíveis fatores associados à ocorrência de acidentes de trabalho e gravidade dos acidentes a partir de análises estatísticas de dados, em especial os fatores idade e tempo de experiência em uma usina de grande porte, produtora de açúcar, etanol e energia, localizada no interior do estado de São Paulo. 
Essa pesquisa é de caráter quantitativo e tomou como base a pesquisa documental por meio do levantamento no banco de dados de uma empresa grande porte do setor sucroalcooleiro. A coleta dos dados foi realizada sobre a base cadastral dos trabalhadores das organizações, da qual extraiu-se as variáveis independentes que podem estar relacionadas com as respostas de interesse (ocorrência de acidentes de trabalho e gravidade do acidente): idade (em anos) e tempo de experiência (em anos) dos trabalhadores. A análise estatística dos dados, foi feita com o objetivo de levantar evidências e confirmar ou não a associação entre as variáveis.

A estrutura do trabalho é composta por 5 seções, mais as referências. As seções são: (1) Introdução, nesta etapa são abordados temas como acidentes do trabalho, a ocorrência dos acidentes e sua relação com o tempo de experiência, expõe-se a importância da pesquisa e seu objetivo; (2) Revisão da literatura, na qual é abordado o tema, condições inseguras no ambiente de trabalho; (3) Método da pesquisa em que é descrito as etapas de desenvolvimento dessa pesquisa; (4) Resultados, que apresenta os resultados obtidos na investigação do banco de dados da empresa com o apoio de ferramentas estatísticas; e (5) Conclusões e considerações finais que expõe as principais conclusões em função da análise dos resultados, assim como sugestões para estudos futuros e limitações da pesquisa; e por fim são enunciadas as referências.

\section{REVISÃO DA LITERATURA}

De acordo com o Instituto Nacional do Seguro Social (2019) acidente de trabalho ou de trajeto é o acidente ocorrido no exercício da atividade profissional a serviço da empresa ou no deslocamento, seja ele para residência ou para o trabalho, e que provoque lesão corporal ou perturbação funcional que cause a perda ou redução (permanente ou temporária) da capacidade para o trabalho ou, em último caso, a morte.

Segundo Freitas (1974, p.26) "o acidente pode sobrevir não só pelas condições técnicas impróprias ou inadequadas, como também por fatores especialmente pessoais e por elementos que delimitam o contexto humano de situação de trabalho", sendo complementado por Filsner (2013) que diz que os acidentes de trabalho não ocorrem involuntariamente, eles são influenciados também por fatores comportamentais dos trabalhadores, que levam a uma maior exposição aos riscos ocupacionais. 
Em uma investigação feita por Freitas (2011) analisando os riscos que o trabalhador tem de se envolver em acidentes durante os exercícios do trabalho, o autor relata que os trabalhadores do setor sucroalcooleiro compõem a categoria profissional com maior risco de sofrer acidente de trabalho, por desenvolverem um grande conjunto de atividades, como a preparação do solo para o plantio, transporte e armazenagem de produtos e insumos agrícolas, além de incontáveis atividades desenvolvidas paralelamente como abertura de canais de irrigação e drenagem, atividades de construção e manutenção, controle de pragas e doenças, entre outros. Também é utilizado ferramentas, substâncias, máquinas e produtos na atividade agrícola que podem trazer riscos a seus usuários, comprometendo a saúde dos trabalhadores. Adas (2012) complementa destacando que os problemas associados aos acidentes de trabalho são muito maiores quando envolvem trabalhadores do setor sucroalcooleiro

Para Vilar et al. (2012) muitas atividades realizadas no ambiente industrial do setor sucroalcooleiro ainda continuam expondo os trabalhadores a riscos de acidentes; na opinião do pesquisador a falta de medidas consistentes de segurança e a ausência da formação de equipes de segurança providas por uma ferramenta de gerenciamento eficaz, são as principais razões desta exposição, o que revela a necessidade de uma política de gestão de riscos mais apropriada e com uma maior participação dos trabalhadores.

Chale (2013) relata que o setor sucroalcooleiro coloca o Brasil em posição de destaque no mercado internacional, sendo o maior produtor de açúcar e álcool do mundo, seguido da Índia e Austrália, além de ser o principal produtor e exportador destes produtos, também lidera o conhecimento da biotecnologia da cana juntamente com a Austrália e África do sul. Porém, mesmo que seja um setor em franco crescimento tanto na produção quanto na economia com todos os processos de industrialização e tecnologia, a condição de trabalho neste setor é deficiente e prejudicial aos trabalhadores que sofrem com os danos.

Ribeiro (2015) em uma análise de 1004 acidentes de trabalho que foram documentados pelo SINAM, identificou que $43,1 \%$ dos acidentados eram trabalhadores que estavam no cargo a pouco tempo (no máximo 1 ano), 37,1\% aqueles que estavam de 1 a 10 anos no cargo e 19,8\% são os que estão a mais tempo na ocupação, com mais de 10 anos. Dados semelhantes foram obtidos por Rodrigues (2017) que, em relação ao tempo de experiência, atestou que os acidentes de trabalho diminuíam em função do aumento da experiência, mostrando que 40,7\% (22) dos acidentados possuíam menos que 
10 anos de experiência, 29,6\% (16) entre 11 e 20 anos, de 21 a 30 anos 18,5\% (10) e apenas $11,1 \%$ (6) com mais de 30 anos de experiência.

Seguindo os resultados obtidos por vários autores pode-se notar que a maioria aponta para uma relação inversamente proporcional entre o tempo de experiência e o envolvimento em acidentes, ou seja, quanto maior o tempo de experiência, menor a chance da ocorrência de acidentes, fato corroborado por Carregaro e Coury (2007) que envolveu 31 pessoas sadias do sexo masculino, com foco na postura dos indivíduos ao realizarem a atividade de levantamento, abaixamento ou carregamento de caixas. A pesquisa mostrou que ao movimentar cargas os trabalhadores inexperientes ou que possuem pouca experiência tendem a apresentar a postura da coluna mais fletida e com uma maior inclinação lateral, podendo acarretar riscos a saúde ou acidentes, enquanto que os mais experientes adotam posturas mais simétricas, mantendo os discos da coluna menos comprimidos durante a movimentação. Os autores também afirmam que os treinamentos passados aos trabalhadores não devem ser somente com foco em fazer da "maneira correta" e sim devem ensinar a identificar e reconhecer situações de risco.

Entretanto, mesmo que a maioria dos estudos indique que a taxa de acidentes tende a diminuir em relação ao maior tempo de experiencia, para Soares (2008) o acidente de trabalho ocorre quando os riscos existentes nas atividades laborais são desconhecidos pelos trabalhadores ou muitas vezes por serem desprezados pelos funcionários de mais tempo de empresa, mostrando assim que os trabalhadores com mais experiência tendem a se acidentar com mais frequência realizando as suas tarefas de rotina.

Teixeira e Freitas (2003) investigaram 58.204 acidentes do trabalho registrados no interior paulista de 1997 e 1999, envolvendo trabalhadores do setor rural, e observaram que 40,3\% destes (24.843 acidentes) envolviam os trabalhadores do setor produtivo da cana de açúcar, sendo que destes, $85 \%$ eram homens e $83 \%$ deles tinham menos de 40 anos de idade, e que $60 \%$ ao menos tinham 30 anos. A pesquisa aponta que as principais causas envolveram: as ferramentas de trabalho como facão e o podão, objetos cortantes, traumatismos ou lesões causadas por instrumentos do trabalho e o contato com animais e plantas venenosas. Também afirmam que doenças do trabalho como lesões por esforço repetitivos, estresse e mal súbito aparecem de forma cada vez mais frequente no cotidiano destes trabalhadores.

Um estudo realizado por Adas (2012), mostra que os trabalhadores mais jovens se envolvem mais em acidentes de trabalho em comparação aos trabalhadores mais velhos, 
sendo que do total de $98,8 \%$ da população acidentada, $47,17 \%$ são indivíduos de 18 a 24 anos de idade, $28,30 \%$ de 25 a 34 anos, $16,98 \%$ de 35 a 44 anos, e 7,55\% de 45 a 54 anos.

Em estudos feitos por Salminen (2004), foi relacionado a idade do trabalhador com a ocorrência de acidentes, e para acidentes não fatais o estudo foi feito em 18 países e destes os 3 mais citados são Estados Unidos (22 estudos), Suécia (9) e Canada (5). A pesquisa destaca que 56\% dos acidentes acometem trabalhadores menores de 25 anos, $17 \%$ os de mais idade e $27 \%$ não apresentam diferença entre os grupos etários. Porém, no caso de acidentes fatais, os países mais mencionados foram Estados Unidos (25), Austrália (5) e Suécia (3), e as estatísticas mostraram que a maioria dos trabalhadores de idade abaixo de 25 anos (64\%) tiveram uma taxa de mortalidade menor em relação aos mais velhos.

Resultados semelhantes foram obtidos em outros setores, como no setor da saúde, no qual Rodrigues (2017) analisou acidentes de trabalho dentre trabalhadores de um hospital universitário entre os anos de 2013 a 2016 com enfoque na etária e no tempo de experiência. Em relação a faixa etária dos trabalhadores acidentados, o autor constatou que a maioria estava na faixa etária de 31 a 40 anos, sendo 37,2\% (425) do total, seguidos por 25,6\% (293) que possuem de 41 a 50 anos, 21,5\% (246) de 51 a 60 anos, 8,8\% (101) de 21 a 30 anos, 6,7\% (77) de 61 a 70 anos e 0,2\% (2) que possuíam mais de 70 anos.

A identificação e a compreensão dos fatores associados aos acidentes de trabalho se apresentam alinhados a filosofia de prevenção destes eventos, contrapondo em grande parte a tradicional tratativa presente nos ambientes laborais de cunho mais reativo. $\mathrm{O}$ esforço por identificar os aspectos que podem estar ligados aos acidentes, como neste caso a idade e o tempo de experiência, revela nuances que merecem ser consideradas nas políticas segurança e saúde ocupacionais das instituições. De um modo geral, a análise da literatura revelou consenso quanto aos aspectos investigados e seu papel na ocorrência de acidentes, como foi o caso da idade cronológica dos indivíduos, que se mostrou estar inversamente relacionada a probabilidade da ocorrência dos acidentes (ADAS, 2012; RODRIGUES, 2017), relação que também foi observada no caso do fator tempo de experiencia (RIBEIRO, 2015), que aponta que a taxa de acidentes é maior para os funcionários novos com menos de 1 ano. Evidências científicas como essas reforçam a necessidade de busca por maiores esclarecimentos e comprovações destes fenômenos para que as políticas de segurança delas decorrentes tenham mais consistências e sejam mais eficientes. 


\section{MÉTODO DA PESQUISA}

Este estudo quantitativo avaliou a influência dos fatores idade e tempo de experiência na ocorrência dos acidentes de trabalho dos funcionários de uma usina de grande porte, produtora de açúcar, etanol e energia, localizada no interior do estado de São Paulo.

A pesquisa apoiou-se em 2 fontes de dados: bibliográfica, para o levantamento das evidências científicas acerca da relação entre os fatores e a ocorrência dos eventos de acidentes, e documental (base de dados cadastral dos funcionários da organização, e registros dos acidentes de trabalho).

A coleta dos dados referentes aos trabalhadores da empresa tomou como base os registros dos indivíduos ativos que atuaram nos anos safras 2015/2016 e 2016/2017, o que contabilizou um total de 770 indivíduos com 56 registros de acidentes de trabalho no período.

Uma primeira variável resposta ou variável dependente de interesse da pesquisa é uma variável aleatória binaria relacionada ao envolvimento de cada funcionário em acidentes de trabalho dada por dois valores codificados: 0 - para o trabalhador que não se envolveu em acidente, e 1 - para o trabalhador que se envolveu em acidente. Uma segunda variável resposta de interesse é dada pela gravidade do acidente de trabalho, medida com base no número de dias em que o funcionário ficou afastado de suas funções, estratificada em 3 categorias ( 0 - para aqueles trabalhadores que não se envolveram em acidente, 1 - para aqueles trabalhadores que se envolveram em acidente de baixa gravidade, com até 15 dias de afastamento, e 2 - para aqueles trabalhadores que se envolveram em acidentes de alta gravidade, com afastamento de suas funções por período superior a 15 dias), como pode ser melhor observado no Quadro 1.

As variáveis de entrada também denominadas variáveis independentes ou covariáveis da pesquisa foram idade categorizada (1 - para trabalhadores até 29 anos de idade, 2 - de 30 a 39 anos de idade, 3 - de 40 a 49 anos de idade, e 4 - acima dos 50 anos de idade), tempo de experiência categorizado (1 - para trabalhadores com até 02 anos de experiência, 2 - para trabalhadores com tempo de experiência de 3 anos, 3 - para trabalhadores com tempo de experiência de 4 anos, e 4 - para trabalhadores com tempo de experiência acima de 5 anos), e setor onde o funcionário desenvolve suas atividades (0 - administrativo, 1- agrícola, e 2 - indústria), como pode ser observado no Quadro 2. 
Quadro 1 - Categorização das variáveis dependentes (respostas) analisadas.

\begin{tabular}{|c|c|}
\hline Variáveis dependentes (VD) & Descrição \\
\hline ENVOLV. EM ACIDENTES & $\begin{array}{l}\text { Envolvimento do profissional em acidente de trabalho: } \\
0 \text { - Profissional que não se envolveu em acidente } \\
1 \text { - Profissional que se envolveu em acidente }\end{array}$ \\
\hline GRAVIDADE DO ACIDENTE & $\begin{array}{l}\text { Classificação do acidente de acordo com sua gravidade: } \\
0 \text { - Não se envolveu em acidente } \\
1 \text { - Envolveu-se em acidente de baixa gravidade, aquele com até } 15 \text { dias } \\
\text { afastado } \\
2 \text { - Envolveu-se em acidentes de alta gravidade, aquele acima de } 15 \text { dias } \\
\text { afastado }\end{array}$ \\
\hline
\end{tabular}

Fonte: Os próprios autores.

Quadro 2 - Categorização das variáveis independentes (covariáveis) analisadas.

\begin{tabular}{|c|l|}
\hline Variáveis independentes (VI) & \multicolumn{1}{|c|}{ Descrição } \\
\hline & Idade em anos, obedecendo a seguinte classificação: \\
& 1 - para trabalhadores até 29 anos de idade \\
& 2 - de 30 a 39 anos de idade \\
& 3 - de 40 a 49 anos de idade \\
& 4 - acima dos 50 anos de idade \\
\hline IDADE & O tempo de experiência segue assim classificado: \\
& 1 - tempo de experiência de até 02 anos \\
& 2 - tempo de experiência de 03 anos \\
& 3 - tempo de experiência de 04 anos \\
& 4 - tempo de experiência acima de 05 anos \\
\hline SETOR & Setor de trabalho do funcionário, sendo classificado como: \\
& 0 - Administrativo \\
& 1 - Agrícola \\
& 2 - Indústria \\
\hline
\end{tabular}

Fonte: Os próprios autores.

A análise dos dados coletados foi realizada usando o software Minitab® versão 16, as interpretações dos resultados foram inicialmente obtidas a partir de uma análise descritiva dos dados; posteriormente com a finalidade de descobrir evidências das possíveis associações entre as variáveis dependentes e variáveis independentes, foram consideradas as seguintes técnicas estatísticas: testes qui-quadrado de Pearson para verificar possíveis dependências para dados categóricos e modelos de regressão logística binária e politômica, que capturam o efeito conjunto das covariáveis sobre as variáveis respostas de interesse. Para todos os casos foi assumido um nível de significância igual a 
$5 \%$, isto é, a rejeição da hipótese de nulidade de cada teste estatístico foi considerada para valores-p $<0,05$.

\section{RESULTADOS}

Os 770 trabalhadores que foram avaliados, como pode ser observado na Tabela 1, apresentaram um percentual de envolvimento em acidentes da ordem de 7\%, com 56 eventos no período da investigação, referente aos dois anos safra (2015/16 e 2016/17), sendo que destes, 12 foram considerados de alta gravidade.

Tabela 1 - Distribuição dos trabalhadores por variáveis investigadas

\begin{tabular}{|c|c|c|}
\hline Variáveis & $\mathbf{N}$ & $\%$ \\
\hline \multicolumn{3}{|l|}{ Envolvimento em acidentes } \\
\hline não & 714 & 93 \\
\hline $\operatorname{sim}$ & 56 & 7 \\
\hline \multicolumn{3}{|l|}{ Gravidade do acidente } \\
\hline Não se envolveu em acidente & 714 & 93 \\
\hline Acidente de baixa gravidade & 44 & 6 \\
\hline Acidente de alta gravidade & 12 & 1 \\
\hline \multicolumn{3}{|l|}{ Idade } \\
\hline até 29 anos & 171 & 22 \\
\hline de 30 a 39 anos & 231 & 30 \\
\hline de 40 a 49 anos & 189 & 25 \\
\hline acima de 50 anos & 179 & 23 \\
\hline \multicolumn{3}{|l|}{ Tempo de experiência } \\
\hline até 2 anos de experiência & 135 & 17 \\
\hline 3 anos de experiência & 120 & 16 \\
\hline 4 anos de experiência & 140 & 18 \\
\hline 5 anos de experiência ou mais & 375 & 49 \\
\hline \multicolumn{3}{|l|}{ Setor } \\
\hline Administrativo & 24 & 3 \\
\hline Agrícola & 608 & 79 \\
\hline Industrial & 138 & 18 \\
\hline
\end{tabular}

Fonte: A empresa do estudo.

Quanto a idade dos participantes, é possível observar que aproximadamente metade (52\%) possuem até 40 anos, com 23\% dos indivíduos acima de 50 anos, o que demostra uma distribuição relativamente proporcional dentro dos quartis, no entanto, esta característica não se apresenta da mesma forma quanto ao tempo de experiência. Observa- 
se que $83 \%$ dos trabalhadores tem no mínimo 3 anos de experiência na atividade e quase a metade possui pelo menos 5 anos de tempo de empresa. Este aspecto é considerado importante, uma vez que a literatura associa tempo de experiência a probabilidade de acidentes, e a considerar que o funcionário mais experiente, tende a ser o mais treinado para a função, é razoável supor que este grupo de indivíduos tenha as menores chances de se envolverem em eventos como os acidentes de trabalho. Este raciocínio poderia de igual maneira ser associado a idade cronológica do trabalhador, no entanto outros aspectos também necessitam ser considerados nesta equação como as características do ambiente de trabalho, fatores emocionais, dentre outros.

Nas Tabelas 2 e 3 são apresentadas as frequências de acidentes de acordo com a gravidade para os fatores idade categorizada, tempo de experiência e setor.

Tabela 2 - Frequências da gravidade dos acidentes for níveis dos fatores (idade, experiência).

\begin{tabular}{|c|c|c|c|c|c|c|c|c|c|}
\hline \multirow[t]{2}{*}{ Linhas: } & \multirow{2}{*}{$\frac{\text { id.cat }}{0}$} & \multicolumn{3}{|c|}{ Colunas: grav.acid } & \multirow[t]{2}{*}{ Iinhas: } & exp.cat & \multicolumn{2}{|c|}{ Colunas: } & \multirow{2}{*}{$\begin{array}{l}\text { grav.acid } \\
\text { todos }\end{array}$} \\
\hline & & 1 & 2 & todos & & 0 & 1 & 2 & \\
\hline 1 & $\begin{array}{c}156 \\
91,23 \%\end{array}$ & $\begin{array}{c}13 \\
7,60 \%\end{array}$ & $\begin{array}{c}2 \\
1,17 \%\end{array}$ & $\begin{array}{l}171 \\
100 \%\end{array}$ & 1 & $\begin{array}{c}127 \\
94,07 \%\end{array}$ & $\begin{array}{c}5 \\
3,70 \%\end{array}$ & $\begin{array}{c}3 \\
2,22 \%\end{array}$ & $\begin{array}{l}135 \\
100 \%\end{array}$ \\
\hline 2 & $\begin{array}{c}206 \\
89,18 \% \\
\end{array}$ & $\begin{array}{c}18 \\
7,79 \% \\
\end{array}$ & $\begin{array}{c}7 \\
3,03 \%\end{array}$ & $\begin{array}{l}231 \\
100 \% \\
\end{array}$ & 2 & $\begin{array}{c}116 \\
96,67 \% \\
\end{array}$ & $\begin{array}{c}3 \\
2,50 \% \\
\end{array}$ & $\begin{array}{c}1 \\
0,83 \%\end{array}$ & $\begin{array}{l}120 \\
100 \% \\
\end{array}$ \\
\hline 3 & $\begin{array}{c}179 \\
94,71 \%\end{array}$ & $\begin{array}{c}8 \\
4,23 \%\end{array}$ & $\begin{array}{c}2 \\
1,06 \%\end{array}$ & $\begin{array}{l}189 \\
100 \%\end{array}$ & 3 & $\begin{array}{c}129 \\
92,14 \%\end{array}$ & $\begin{array}{c}8 \\
5,71 \%\end{array}$ & $\begin{array}{c}3 \\
2,14 \%\end{array}$ & $\begin{array}{l}140 \\
100 \%\end{array}$ \\
\hline 4 & $\begin{array}{c}174 \\
97,21 \% \\
\end{array}$ & $\begin{array}{c}4 \\
2,23 \% \\
\end{array}$ & $\begin{array}{c}1 \\
0,56 \%\end{array}$ & $\begin{array}{l}179 \\
100 \% \\
\end{array}$ & 4 & $\begin{array}{c}343 \\
91,47 \% \\
\end{array}$ & $\begin{array}{c}27 \\
7,20 \% \\
\end{array}$ & $\begin{array}{c}5 \\
1,33 \% \\
\end{array}$ & $\begin{array}{l}375 \\
100 \% \\
\end{array}$ \\
\hline
\end{tabular}

Fonte: Os próprios autores.

Tabela 3 - Frequências da gravidade dos acidentes for níveis do fator (setor).

\begin{tabular}{ccccc}
\hline Linhas: & setor & \multicolumn{2}{c}{ Colunas: } & \multicolumn{2}{c}{ grav.acid } \\
\hline 0 & 0 & 1 & 2 & todos \\
\hline 1 & 24 & 0 & 0 & 24 \\
& $100 \%$ & $0 \%$ & $0 \%$ & $100 \%$ \\
\hline 2 & 572 & 30 & 6 & 608 \\
& $94,08 \%$ & $4,93 \%$ & $0,99 \%$ & $100 \%$ \\
\hline & 119 & 13 & 6 & 138 \\
& $86,23 \%$ & $9,42 \%$ & $4,35 \%$ & $100 \%$ \\
\hline
\end{tabular}

Fonte: Os próprios autores.

A partir dos resultados das Tabelas 2 e 3 foram identificados indícios empíricos de que as frequências de gravidade de acidentes nos diferentes níveis de idade e setor são diferentes. Para o tempo de experiência foi necessária uma análise estatística mais apropriada, para revelar se há diferenças significativas de frequências de gravidade de acidentes para a categoria (anos de experiência). 
Nas Tabelas 4 e 5 são apresentadas as frequências de ocorrência de acidentes para os diferentes níveis dos fatores idade categorizada, tempo de experiência e setor.

Tabela 4 - Frequências das ocorrências dos acidentes for níveis dos fatores (idade, experiência).

\begin{tabular}{|c|c|c|c|c|c|c|c|}
\hline & : id.cat & Coluna & as: acid & Linhas & exper. & at & lunas: acid \\
\hline & 0 & 1 & todos & & 0 & 1 & todos \\
\hline 1 & 156 & 15 & 171 & 1 & 127 & 8 & 135 \\
\hline & $91,23 \%$ & $8,77 \%$ & $100 \%$ & & $94,07 \%$ & $5,93 \%$ & $100 \%$ \\
\hline 2 & 206 & 25 & 231 & 2 & 116 & 4 & 120 \\
\hline & $89,18 \%$ & $10,82 \%$ & $100 \%$ & & $96,67 \%$ & $3,33 \%$ & $100 \%$ \\
\hline 3 & 179 & 10 & 189 & 3 & 129 & 11 & 140 \\
\hline & $94,71 \%$ & $5,29 \%$ & $100 \%$ & & $92,14 \%$ & $7,86 \%$ & $100 \%$ \\
\hline 4 & 174 & 5 & 179 & 4 & 343 & 32 & 375 \\
\hline & $97,21 \%$ & $2,79 \%$ & $100 \%$ & & $91,47 \%$ & $8,53 \%$ & $100 \%$ \\
\hline
\end{tabular}

Fonte: Os próprios autores.

Tabela 5 - Frequências das ocorrências dos acidentes for níveis do fator (setor).

\begin{tabular}{lccc}
\hline Linhas: & setor & Colunas: & acid \\
\hline & 0 & 1 & todos \\
\hline 0 & 24 & 0 & 24 \\
& $100 \%$ & $0 \%$ & $100 \%$ \\
\hline 1 & 572 & 36 & 608 \\
& $94,08 \%$ & $5,92 \%$ & $100 \%$ \\
\hline 2 & 119 & 19 & 138 \\
& $86,23 \%$ & $13,77 \%$ & $100 \%$ \\
\hline \multicolumn{4}{c}{ Fonte: Os próprios autores. }
\end{tabular}

A partir dos resultados das Tabelas 4 e 5 também é observado que há indícios empíricos de que as frequências de ocorrências de acidentes nos diferentes níveis de idade e setor são estatisticamente diferentes. Para o tempo de experiência foi necessária uma análise estatística mais apropriada, para revelar se há diferenças significativas de frequências de ocorrências de acidentes para a categoria (anos de experiência).

A partir das evidências empíricas levantadas (resultados das Tabelas 2, 3, 4 e 5), faz-se necessário o aprofundamento das análises estatísticas para que se possa comprovar o papel destes fatores na ocorrência dos acidentes de trabalho.

A primeira análise estatística dos dados usou testes qui-quadrado de Pearson de dependência para descobrir se existe associação entre as variáveis categóricas de entrada (independentes) e as variáveis de saída (dependentes) considerando tabelas de contingência construídas a partir dos dados da amostra coletada (MONTGOMERY; RUNGER, 2010). A hipótese nula (ou de nulidade) especifica que as variáveis não estão 
associadas, em outras palavras, elas são independentes. A hipótese alternativa especifica que as variáveis estão associadas, ou são dependentes estatisticamente.

A partir dos resultados da análise estatística dos dados categóricos baseada em testes qui-quadrado de independência envolvendo as variáveis de entrada (idade, tempo de experiência e setor) e as variáveis resposta (envolvimento com acidentes e gravidade destes eventos), apresentados na Tabela 6, confirmam as evidências empíricas obtidas previamente a partir da análise descritiva dos dados, isto é, verifica-se uma associação significativa entre a idade e a ocorrência de acidentes e também entre a idade e a gravidade dos acidentes (valores-p iguais a 0,009 e 0,041 respectivamente). Também é observado uma associação significativa entre o setor e a ocorrência dos eventos (valor-p igual a 0,02). As relações existentes entre as variáveis também podem ser visualizadas e complementadas a partir das Figuras 1 e 2 que apresentam os gráficos, que mostram o comportamento das variáveis em função das respostas.

Como pode ser notado na Figura 1 tanto as frequências dos acidentes quanto a sua gravidade tendem a diminuir com a idade, ilustrando a associação revelada no teste estatístico mencionado anteriormente. Com relação ao setor da empresa ( 0 -adminstrativo, 1-agrícola e 2-indústria), é possível observar na Figura 2 que o setor que mais se destaca em termos da frequência dos acidentes de trabalho é o industrial, o que em parte pode ser entendido pelo fato de apresentar maiores riscos de acidentes em função do número de equipamentos com elementos rotativos e elevada temperatura, como é o caso do ambiente fabril da usina estudada. O fator tempo de experiência não mostrou associação significativa com as variáveis dependentes envolvimento em acidentes e gravidade do acidente (valores-p > 0,05). Quanto a gravidade dos eventos e sua relação com o setor, não foi possível rodar o teste estatístico (qui-quadrado de Pearson) para verificar tal relação, pois em algumas celas da tabela de contingência correspondente havia um número muito pequeno de observações (menor do que 5) o que impede a realização de um teste estatístico assintótico. Essa possível relação pode ser observada a partir de gráficos de intervalos de confiança para as medias (acidentes e gravidade dos acidentes em cada nível de setor). No Gráfico 2 observa-se que ocorrência de acidentes e gravidade dos acidentes estão associados com os níveis do setor, pois os intervalos de confiança 95\% para as medias (ocorrência acidentes e gravidade dos acidentes) não são superpostos (as taxas medias diferem em cada nível do setor). 
Tabela 6 - Valores-p da análise estatística baseada em testes qui-quadrado de independência.

\begin{tabular}{l|c|c}
\hline \multirow{2}{*}{ Variáveis de entrada } & \multicolumn{2}{|c}{ Variáveis resposta } \\
\cline { 2 - 3 } & Envolvimento em acidentes & Gravidade do acidente \\
\hline Idade & 0,009 & 0,041 \\
Tempo de experiência & 0,248 & 0,405 \\
Setor & 0,02 & \\
\hline
\end{tabular}

Fonte: Os próprios autores.

Figura 1 - Intervalos de confiança 95\% para as médias das respostas (envolvimento em acidentes e gravidade) para os diferentes níveis de idade (categorizada).

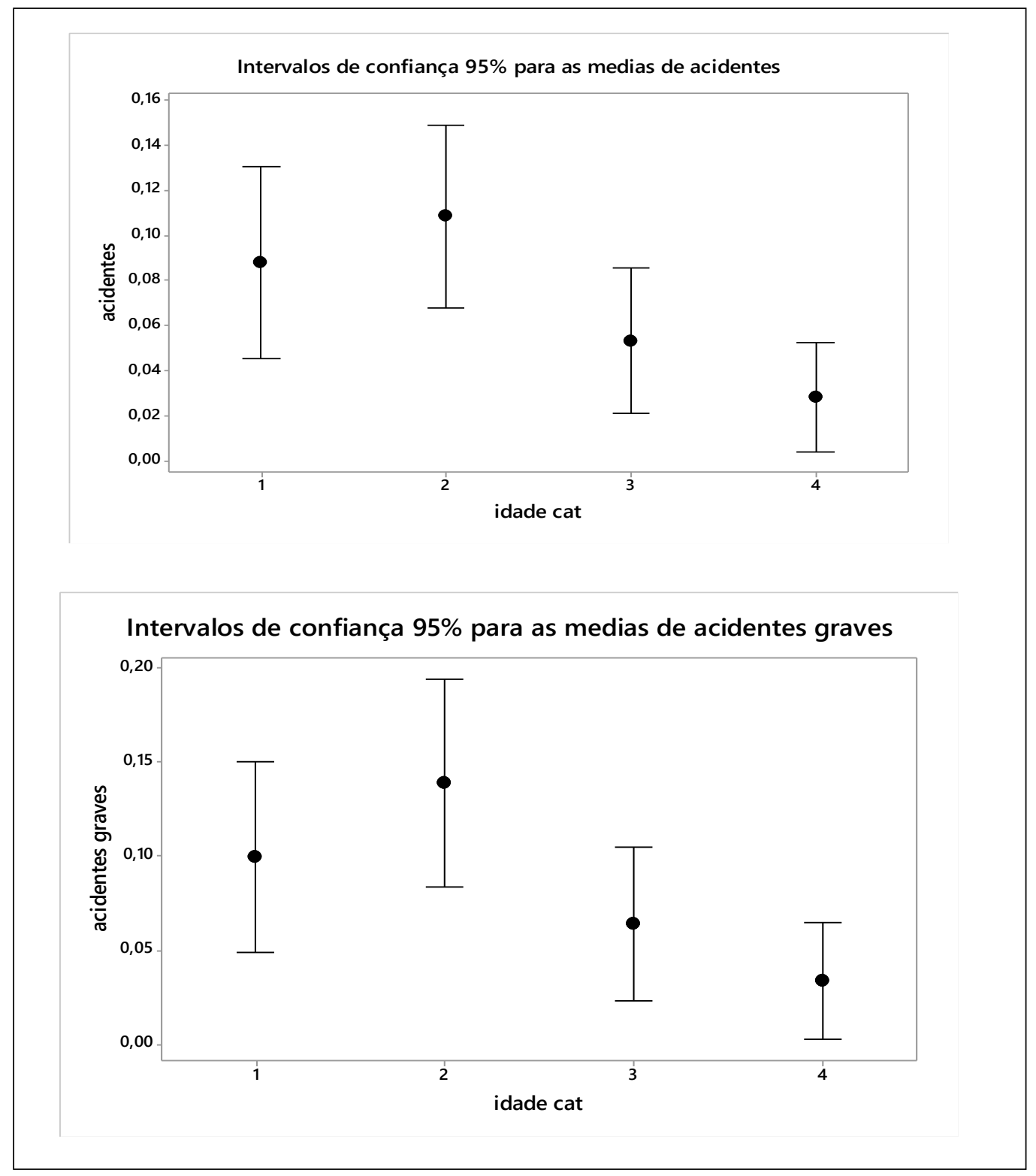

Fonte: Os próprios autores. 
Figura 2 - Intervalos de confiança 95\% para as medias das respostas (envolvimento em acidentes e gravidade dos acidentes) para os diferentes níveis de setor

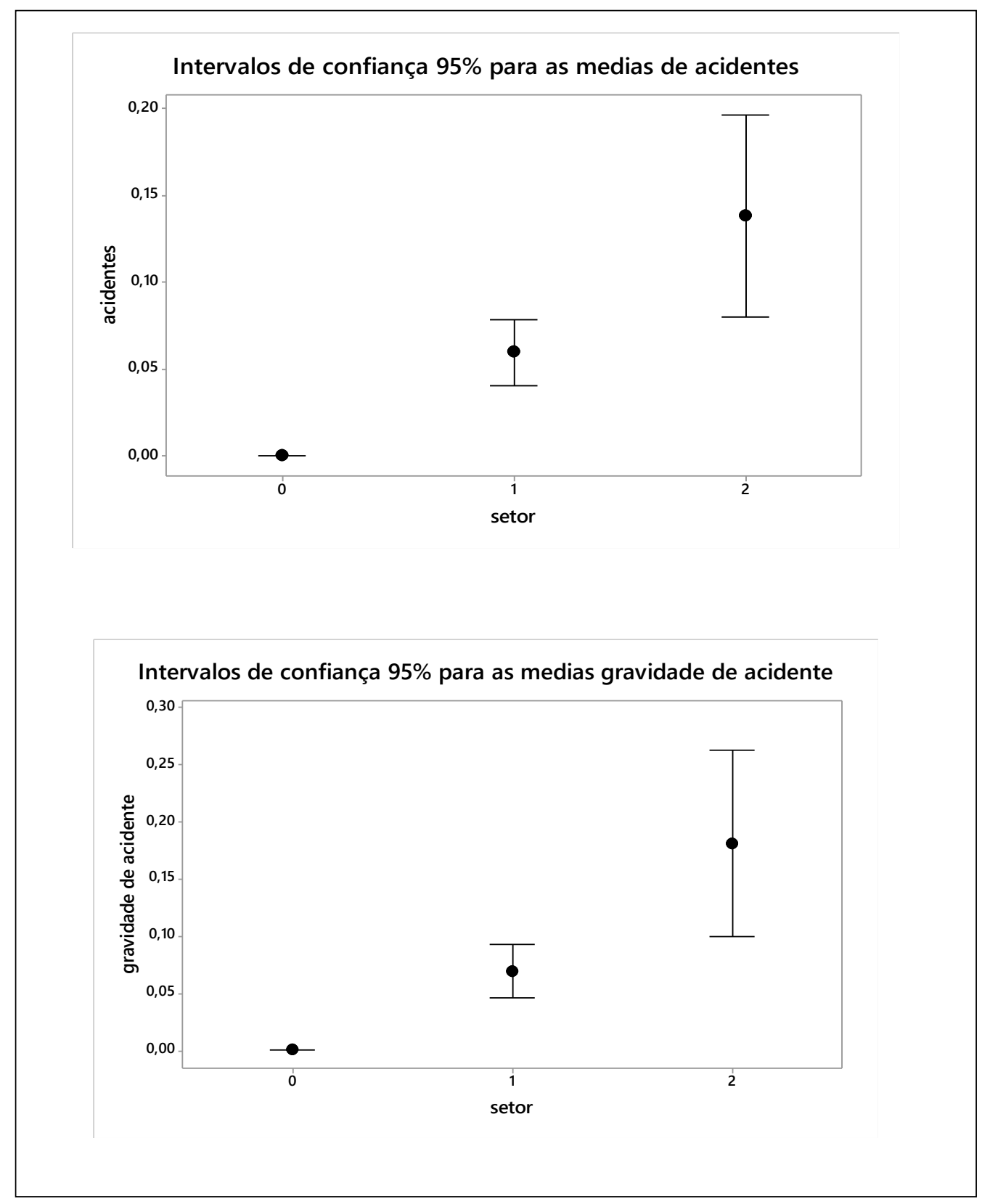

Fonte: Os próprios autores.

Apesar das evidências estatísticas apresentadas, faz-se necessário avaliar o efeito que as variáveis exercem entre si, o que pode ser feito com o uso de teste estatístico apropriado que capture o efeito conjunto das variáveis sobre as respostas avaliadas. O uso de modelos de regressão apropriados (MONTGOMERY; RUNGER, 2010) para respostas categóricas (regressão logística e regressão politômica), permite que se capture esse efeito 
conjunto das variáveis independentes (idade, experiência e setor) sobre a variável dependente que neste caso são o envolvimento em acidentes de trabalho e sua gravidade.

A regressão logística é uma técnica recomendada para situações em que a variável dependente é de natureza dicotômica ou binária. Quanto às variáveis independentes, tanto podem ser categóricas ou não. A regressão logística é um recurso que permite estimar a probabilidade associada à ocorrência de determinado evento em face de um conjunto de variáveis explanatórias, buscando estimar a probabilidade da variável dependente assumir um determinado valor em função dos conhecidos de outras variáveis, em que os resultados da análise ficam contidos no intervalo de zero a um.

$\mathrm{Na}$ análise estatística de dados usando modelos de regressão logística, a probabilidade de ocorrência de um evento pode ser estimada diretamente, sendo também possível identificar as variáveis independentes que são estatisticamente significativas (valor-p < 0,05). A Tabela 7 apresenta os resultados do ajuste de um modelo de regressão logística (uso do software Minitab®) assumindo a resposta binaria (ocorrência ou não de acidentes). As variáveis significativas que afetam o envolvimento em acidentes são idade e setor (valores-p $<0,05$ ). A Tabela 7 também apresenta informações adicionais da análise de regressão logística para o fator envolvimento em acidentes, como os estimadores dos coeficientes de regressão estimados por métodos de máxima verossimilhança (métodos numéricos iterativos) para cada variável, com destaque para a idade e setor, sendo respectivamente dados por - 0,0353 e 0,837, revelando que:

- O aumento da idade diminui a probabilidade de ocorrência de acidentes de trabalho; este resultado está de acordo com os gráficos da Figura 1;

- Quanto maior o número representativo da categoria do setor (0 administração; 1 - agrícola; 2 - indústria), maior a probabilidade de ocorrência de acidente de trabalho; este resultado está de acordo com os gráficos da Figura 2;

- O fator experiência não mostra efeito significativo na resposta ocorrência de acidentes; este resultado está de acordo com os resultados obtidos usando testes qui-quadrado para variáveis categóricas (ver Tabela 2). Apesar disso quando se considera um nível de significância igual à 10\% observa-se algum efeito de experiência na ocorrência de acidentes (valor-p $=0,078<0,10$ ). 
Tabela 7 - Análise de regressão logística para a resposta ocorrência de acidentes

\begin{tabular}{lccc}
\hline Termo & $\begin{array}{c}\text { Estimador } \\
\text { coeficiente }\end{array}$ & $\begin{array}{c}\text { EP } \\
\text { Coeficiente }\end{array}$ & Valor-p \\
\hline Constante & $-2,963$ & 0,898 & \\
Idade & $-0,0353$ & 0,0181 & 0,043 \\
Experiência & 0,0885 & 0,0481 & 0,078 \\
Setor & 0,837 & 0,300 & 0,006 \\
\hline
\end{tabular}

Fonte: Os próprios autores.

Uma última análise estatística dos dados assume um modelo de regressão politômica para a resposta gravidade do acidente (três categorias). $\mathrm{O}$ uso de um modelo de regressão politômica avaliou a relação existente entre a variável dependente categórica, gravidade dos acidentes de trabalho (0-não se envolveu em acidente, 1-se envolveu em acidente de baixa gravidade e 2-se envolveu em acidente de alta gravidade), com as variáveis independentes já destacadas anteriormente.

Para efeito de análise e uso da referida técnica estatística (regressão politômica), por se tratar de uma avaliação que envolve mais de 2 categorias, foi tomada a categoria 0 (não se envolveu em acidentes de trabalho) como sendo a de referência. Sendo assim, a análise se desenvolveu avaliando as demais categorias com relação a de referência, ou seja, quais as variáveis independentes estão associadas a mudança da categoria de zero (0) para um (1) e quais as variáveis estão associadas a mudança da categoria de zero (0) para dois (2).

A Tabela 8 apresenta os resultados da análise para o caso das duas comparações, ou seja, comparando a categoria 0 com a 2 e comparando a categoria 0 com a 1 (uso do software Minitab®). A interpretação dos resultados da Tabela 8, deve seguir a seguinte linha de indagação: quais variáveis realmente diferenciam os indivíduos que não sofrem acidentes (categoria 0), daqueles que sofrem acidentes graves (categoria 2)? quais variáveis realmente diferenciam os indivíduos que não sofrem acidentes (categoria 0), daqueles que sofrem acidentes leves (categoria 1)?

No caso da primeira análise, o fator que realmente diferencia os trabalhadores que não se envolvem em acidentes daqueles que se envolvem em acidentes com grau elevado de gravidade (2/0) é o setor. Possuindo um coeficiente estimado positivo, igual a 1,52488; isto revela associação positiva entre as variáveis, ou seja, a gravidade dos acidentes está associada aos trabalhadores alocados no setor.

No caso da segunda análise, o fator que realmente diferencia os trabalhadores que não se envolvem em acidentes daqueles que se envolvem em acidentes com grau baixo de gravidade (1/0) é o grau de experiência. Como o respectivo coeficiente estimado é 
positivo $(0,103362)$, isto revela associação positiva entre as variáveis, ou seja, o envolvimento em acidentes de baixa gravidade está relacionado ao grau de experiência do trabalhador, revelando que o aumento do nível de experiência do trabalhador tem sido um preditor do seu envolvimento em acidentes de baixa gravidade.

\section{APRESENTAÇÃO DA SÍNTESE DAS ANÁLISES}

No Quadro 3 é apresentado uma síntese das análises descritivas das Variáveis Independentes (VI) para com as Variáveis Dependentes (VD), que destaca as categorias mais significativas dentro da análise, sendo complementada pela Tabela 9, que apresenta os resultados da análise baseada no teste qui-quadrado de independência dos dados categóricos, destacando qual variável independente apresenta relação estatística significativa para com a variável dependente analisada.

Tabela 8 - Resultados da análise de regressão politômica para as variáveis independentes.

\begin{tabular}{lcccccc}
\hline \multicolumn{1}{c}{ Preditor } & $\begin{array}{c}\text { Estimador } \\
\text { coeficiente }\end{array}$ & $\begin{array}{c}\text { EP } \\
\text { Coeficiente }\end{array}$ & $\begin{array}{c}\text { Estatística- } \\
\mathbf{Z}\end{array}$ & $\begin{array}{c}\text { Valor- } \\
\mathbf{p}\end{array}$ & $\begin{array}{c}\text { Probabilidade } \\
\text { Relação }\end{array}$ & $\begin{array}{c}\text { I.C. 95\% } \\
\text { Inferior }\end{array}$ \\
Superior
\end{tabular}

Fonte: Os próprios autores.

Quadro 3 - Síntese das análises descritivas.

\begin{tabular}{|c|c|c|}
\hline Variáveis & Envolvimento em acidentes & Gravidade do acidente \\
\hline Idade & $\begin{array}{c}\text { Menos p/ acima dos } 50 \text { anos } \\
\text { Maior entre } 30 \text { a } 39 \text { anos }\end{array}$ & $\begin{array}{c}\text { Menos p/ acima dos } 50 \text { anos } \\
\text { Maior entre } 30 \text { a } 39 \text { anos }\end{array}$ \\
\hline Experiência & $\begin{array}{l}\text { Menor p/ quem tem } 2 \text { anos exp. } \\
\text { Maior p/ } 5 \text { anos exp. ou mais }\end{array}$ & $\begin{array}{l}\text { Menor p/ } 3 \text { anos experiência } \\
\text { Maior p/ } 3 \text { anos experiência }\end{array}$ \\
\hline Setor & $\begin{array}{l}\text { Maior para setor industrial } \\
\text { Menor para administração }\end{array}$ & $\begin{array}{c}\text { Maior para setor industrial } \\
\text { Menor para administração }\end{array}$ \\
\hline
\end{tabular}

Fonte: Os próprios autores. 
Tabela 9 - Síntese das análises baseadas em testes qui-quadrados de independência.

\begin{tabular}{|c|c|c|}
\hline Variáveis & Envolvimento em acidentes & Gravidade do acidente \\
\hline Idade & $\begin{array}{c}\text { Valor-p }=0,009<0,05 \\
(\text { Há dependência estatística })\end{array}$ & $\begin{array}{c}\text { Valor-p }=0,041<0,05 \\
(\text { Há dependência estatística) }\end{array}$ \\
\hline \multirow{2}{*}{ Experiência } & $\begin{array}{c}\text { Valor }-P=0,248, \operatorname{logo} \\
\text { valor }-p>0,05\end{array}$ & $\begin{array}{c}\text { Valor }-P=0,405, \text { logo valor }- \\
p>0,05\end{array}$ \\
\hline & (Não há dep. Estatística) & $\begin{array}{c}\text { (Não há dependência } \\
\text { Estatística) }\end{array}$ \\
\hline \multirow{2}{*}{ Setor } & $\begin{array}{c}\text { Valor }-P=0,02, \log o \\
\text { valor-p<0,05 }\end{array}$ & Não foi possível rodar o \\
\hline & (Há dependência estatística) & $\frac{\text { teste estatístico (amostra }}{\text { pequena) }}$ \\
\hline
\end{tabular}

Fonte: Os próprios autores.

A Tabela 10 mostra a síntese dos resultados obtidos a partir da análise de regressão logística binária e apresenta quais variáveis independentes possuem relação positiva para com a variável dependente (envolvimento em acidentes), e a análise de regressão politômica mostra qual variável independente apresenta relação positiva para com a variável dependente gravidade do acidente.

Tabela 10 - Síntese dos resultados dos testes de regressão.

\begin{tabular}{llccccc}
\hline \multicolumn{1}{c}{ Modelo } & \multicolumn{2}{c}{ Regressão Logística } & \multicolumn{4}{c}{ Regressão politômica } \\
\hline Variáveis & $\begin{array}{c}\text { Envolvimento em acidente } \\
\text { Coeficiente }\end{array}$ & valor-p & $\begin{array}{c}\text { Relação 2/0 } \\
\text { Coeficiente }\end{array}$ & $\begin{array}{c}\text { Gravidade do acidente } \\
\text { valor-p }\end{array}$ & $\begin{array}{c}\text { Relação 1/0 } \\
\text { Coeficiente }\end{array}$ & valor- p \\
\hline Idade & $\mathbf{- 0 , 0 3 5 3}$ & $\mathbf{0 , 0 4 3}$ & $-0,027292$ & 0,454 & $-0,0376516$ & 0,067 \\
Experiência & 0,0885 & 0,078 & $+0,0284423$ & 0,793 & $\mathbf{+ 0 , 1 0 3 3 6 2}$ & $\mathbf{0 , 0 4 7}$ \\
Setor & $\mathbf{0 , 8 3 7}$ & $\mathbf{0 , 0 0 6}$ & $\mathbf{+ 1 , 5 2 4 8 8}$ & $\mathbf{0 , 0 1 1}$ & $+0,638702$ & 0,060 \\
\hline
\end{tabular}

Fonte: Os próprios autores.

A análise estatística de regressão logística envolvendo as variáveis independentes (idade, experiência e setor) e a variável resposta envolvimento com acidentes de trabalho, revelou que para o caso investigado, 2 fatores se apresentam como comuns ao grupo de funcionários que se acidentam, sendo eles a idade e o setor onde trabalham. Como pode ser observado na Tabela 10 e em particular na coluna referente aos coeficientes, o fator idade (coeficiente igual a - 0,0353) apresenta relação negativa com relação ao envolvimento do trabalhador nos acidentes de trabalho, ou seja, quanto maior a idade do trabalhador, menor a sua probabilidade de se envolver nestes tipos de eventos, corroborando com os trabalhos de Parejo-Moscoso, Rubio-Romero e Pérez-Canto (2012), Rodrigues (2017), e Nogueira, Gomes e Sawaia (1981), que apresentaram maior prevalência de acidentes dentre os trabalhadores com faixa etária inferior a 40 anos, o que não foi observado em outros trabalhos como de Ribeiro (2015) e Laflamme e Menckel 
(1995), que concluíram que os acidentes ocorrem com maior frequência em trabalhadores de faixa etária superior a 40 anos devido ao envelhecimento.

O setor onde os trabalhadores exercem suas atividades também foi um aspecto determinante no envolvimento dos indivíduos em acidentes de trabalho, apontando o setor industrial como o que mais acomete trabalhadores. Este fato não é de todo inesperado uma vez que os demais setores investigados (administrativo e agrícola) contam com atividades muito específicas e com pouca exposição do trabalhador ao risco. Como abordado por Freitas (2011) e Adas (2012) a natureza da atividade desenvolvida no setor industrial, caracteriza-se por uma maior proximidade do trabalhador ao risco uma vez que envolve muito serviço de reparo e manutenção de equipamentos em serviço, aspecto este que aumenta o risco de acidentes. No entanto, diversos estudos envolvendo os mesmo segmento econômico estudado, como Queiroz (2017) divergem da afirmação anterior, e destacam que o setor agrícola como sendo o local onde ocorre o maior número de acidentes, seguido pelo setor industrial e por último o administrativo, o que talvez possa ser justificado pelo fato da empresa estudada não possuir mais corte ou plantio manual de cana de açúcar, atividades estas que podem expor o trabalhador a inúmeros riscos, tais como: cortes, escoriações, picadas de animais peçonhentos, LER (Lesões por Esforços Repetitivos), DORT (Distúrbios Osteomusculares Relacionados ao Trabalho) e outros, onde com as atividades $100 \%$ mecanizadas, a empresa estuda diminui a quantidade de trabalhadores braçais e também os riscos.

A análise estatística politômica envolvendo as variáveis independentes (idade, experiência e setor) e a variável resposta gravidade dos acidentes de trabalho, revelou que para o caso investigado, 3 fatores se apresentam como comuns ao grupo de funcionários que se acidentam e cuja gravidade é elevada e leve, sendo eles o nível de experiência, o setor onde trabalham e o número de desvios de comportamento seguro que cometem. Como pode ser observado na Tabela 10 e em particular na coluna coeficientes, nota-se a relação destes fatores para com o grau de gravidade destes eventos.

Quando se analisa o fator experiência e sua relação com a gravidade do acidente observa-se que este apresenta relação positiva para com o envolvimento em acidente com menor gravidade (Relação 1/0), apresentando coeficiente positivo igual a 0,103362 , o que mostra que com o aumento da experiência, aumenta a probabilidade de envolvimento em acidentes de menor gravidade. 
O setor de trabalho também se apresenta com destaque na análise, apresentando relação positiva com o envolvimento em acidentes com gravidade mais elevada (Relação $2 / 0)$, apresentando coeficiente $+1,52488$, apontando que com o aumento do setor ( 0 administrativo, 1-agrícola e 2-industria), aumenta a probabilidade de aumento na gravidade do acidente, não tendo sido encontrado na literatura estudo que tenha relacionado a experiência e o setor com a gravidade do acidente.

\section{CONCLUSÕES E CONSIDERAÇÕES FINAIS}

Essa pesquisa propôs identificar fatores pessoais e profissionais que possam ter relação direta com o envolvimento em acidentes de trabalho e a gravidade destes eventos, em uma empresa do setor sucroalcooleiro, com o objetivo de auxiliar no desenvolvimento e no aprimoramento das estratégias de saúde ocupacional da empresa de modo a contribuir para a redução dos acidentes de trabalho. Diante das evidentes constatações do trabalho, diversas ações podem ser tomadas como:

- Direcionamento de programas de segurança mais específicos aos trabalhadores que se enquadram na faixa etária de 30 a 39 anos, apontados como os mais acometidos pelos acidentes;

- Melhorias no preenchimento dos relatórios de acidente, com identificação da faixa etária do trabalhador acidentado; e

- Desenvolvimento de programas de análise que visem identificar o real motivo pelo qual ocorrem os desvios de comportamento inseguro.

A pesquisa apresenta também oportunidades de ampliação em estudos posteriores, com o acréscimo da variável parte do corpo afetada e também o detalhamento do setor, desmembrando as áreas existentes e analisando-as separadamente, como por exemplo no setor agrícola o preparo de solo, plantio, colheitado, irrigação, e outros e no setor industrial o setor de moagem, geração de vapor, fabricação de açúcar e etanol e também empacotamento de açúcar, destacando-se aqui que alguns destes setores expõem o trabalhador a riscos elevados.

Outra oportunidade importante de estudo seria a identificação dos riscos existentes no setor industrial e nas atividades mecanizadas e verificar a relação entre os fatores pessoais e a exposição a estes riscos, pois a literatura aponta que há poucos os trabalhos 
que avaliam os riscos aos quais os trabalhadores do setor automatizado estão expostos, tanto no Brasil quanto nos demais países.

\section{REFERÊNCIAS}

ADAS, L.C. Acidentes de trabalho no processamento da cana em uma empresa do setor sucroalcooleiro no interior do Estado de São Paulo. 2012, 118 p. Dissertação (Mestrado em Saúde Coletiva). UNESP, Botucatu, 2012.

ALESSI, N. P.; SCOPINHO, R. A. A saúde do trabalhador da cana de açúcar. In: ALESSI, N.P.; PALOCCI FILHO, A.; PINHEIRO, S.A.; SCOPINHO, R.A.; SILVA, G.B. (Org). Saúde e trabalho no sistema único de saúde. São Paulo. Hucitec, p. 121151. 1994.

BATIZ, E.C.; SANTOS, A.F.; LICEA, O.E.A. A postura do trabalho de checkout de supermercado. Produção, v. 19, n. 1, p. 190-201, 2009.

BRASIL. Lei n 8.213, de 24 de julho de 1991. Dispõe sobre os Planos de Benefícios da Previdência Social e dá outras providências.

CARREGARO, R.L.; COURY, H.J.C.G. Análise Biomecânica da coluna durante manuseio de cargas realizado por sujeitos experientes e inexperientes. Fisioterapia e Pesquisa, São Carlos, v. 14, n. 2, p. 57-64, 2007.

CHALE, F. E. C. Perfil de acidentes de trabalho de uma indústria sucroalcooleira em Minas Gerais. Dissertação de Mestrado em Saúde Pública. Universidade Federal de Minas Gerais, Belo Horizonte, 2013.

CRAWFORD, J.O.; GRAVELING, R.A.; COWIE, H.A.; DIXON, K. The health safety and health promotion needs of older workers. Occupational Medicine, May;60(3):18492, 2010. doi: 10.1093/occmed/kqq028

FILSNER, H.F. A revolução industrial e a evolução da engenharia de segurança do trabalho. Monografia (Especialização em Engenharia de Segurança do Trabalho). Faculdade Pitágoras, Belo Horizonte, 2013.

FREITAS, E. A contribuição da Psicologia à prevenção dos acidentes de trabalho. Arquivos Brasileiros de Psicologia Aplicada, Rio de Janeiro, Fundação Getulio Vargas, 26 (1): 25-31, jan./mar. 1974.

FREITAS, R.M.V. Os acidentes do trabalho no interior paulista: o caso da cana de açúcar. Resenha de estatísticas vitais do Estado de São Paulo, 2007. Disponível em: <https://www.seade.gov.br/produtos/midia/spdemografico/SPDemog_julho07.pdf>.Ace sso em: 14 agosto 2016. 
INSTITUTO NACIONAL DO SEGURO SOCIAL. Definição de acidente de trabalho. Disponível em:https://www.inss.gov.br/servicos-do-inss/comunicacao-deacidente-de-trabalho-cat/. Acessado em: 22 de out. 2019.

LAFLAMME, L.E.M.; MENCKEL, E. Aging and occupational accidents: A review of the literature of the last three decades. Safety Science Journal, Amsterdam, Volume 21, Issue 2, December 1995, Pages 145-161.

MONTGOMERY, D. C.; RUNGER, G.C. Applied statistics and probability for engineeers, fifty edition, New York: Wiley, 2010.

OH, J.; SHIN, E.H. Inequalities in nonfatal work injury: the significance of race, human capital, and occupations. Social Science \& Medicine, USA, p. 2173-2182. 2003.

PEGATIN, T.O.; XAVIER, A.A.P. A influência dos curtos tempos de ciclo no desempenho físico-funcional dos trabalhadores em linhas de produção: um estudo piloto. In: XXVIII Encontro Nacional de Engenharia de Produção, 2008, Rio de Janeiro, Anais... Rio de Janeiro, 2008.

RIBEIRO, F.H. Acidentes de trabalho e sua associação com os fatores idade e tempo de experiência do trabalhador: uma pesquisa documental com base no cadastro do sistema SINAN. Dissertação Mestrado Profissional em Engenharia de Produção. UNIARA, Araraquara, 2015, 79 p.

RODRIGUES, V.S. Acidentes de trabalho da enfermagem com perfurocortantes em um hospital universitário: estratégias para prevenção. 81 p. Dissertação (Mestrado em Saúde Social e Saúde do Trabalhador). UFU, Uberlândia, 2017.

SALMINEN, S. Have young workers more injuries than older ones? An International literature review. Journal of Safety Research, v.35, p. 513-521, 2004.

SCOPINHO, R. A. Qualidade total, saúde e trabalho: uma análise em empresas sucroalcooleiras paulistas. RAC. v.4, n. 1, p. 93-112. 2000

SOARES, L.J.P. Os Impactos dos acidentes do trabalho no orçamento brasileiro: uma alternativa política e pedagógica para redução dos gastos. Monografia (Especialização em Orçamento Público), ISC (Instituto Serzedello Corrêa), Brasília, 2008, 56 p.

TEIXEIRA, M. L. P.; FREITAS, R. M. V. B. Acidentes do trabalho rural no interior paulista. São Paulo em perspectiva, v.17, n.2, p.81-90, 2003. 
VILAR, F.M.M.; FRANÇA, J.F.; REUL, L.M.A.; SILVA, R.M. A segurança e saúde ocupacional como meio de desenvolvimento econômico-social em uma empresa sucroalcooleira no nordeste. Revista Brasileira de Agrociência, Pelotas, v. 18, n. 2-4, p. 151-162, 2012.

Recebido em: 01/06/2021

Aprovado em: 20/06/2021

Publicado em: 30/06/2021 